\title{
Case-Study: Mentalization-Based Treatment, A Time-Limited Approach, for A Boy with A Mild Intellectual Disability and Trauma
}

\author{
Masja Juffermans ${ }^{1}$ and Nicole Muller ${ }^{2 *}$ \\ ${ }^{1}$ GZ psychologist, GGZ River Dunes, Netherlands \\ ${ }^{2}$ Working at YOUZ, Netherland
}

Submission: October 15, 2020; Published: December 03, 2020

*Corresponding author: Nicole Muller, Working at YOUZ, Holland, Netherland

\begin{abstract}
In this article, we present a clinical example of Mentalization-Based Treatment for Children (MBT-C) for the treatment of a boy with mild intellectual disability (MID). In the book about MBT-C a Time Limited approach [1] this treatment appeared to be very effective for children with an average IQ. Children with MID can also benefit from this treatment method. Dekker - van der Sande and Stekelenburg [2] emphasized the importance of mentalization promoting guidance for children with visual and intellectual disabilities. However, there are still few case studies of MBT-C in children with MID. A child with MID is identified as having an IQ score between 50-85 in combination with significant limitations in their (social) adaptive functioning. Children with MID learn primarily through experience and repetition and are less verbal compared to other children. This article employs a case study to demonstrate how an MBT-C therapist can properly attune this treatment method to children with MID.
\end{abstract}

Keywords: Children; Intellectual disability; Treatment; Social; Language skills

Abbreviations: MBT-C: Mentalization-Based Treatment for Children; MID: Mild Intellectual Disability; ADHD: Attention-Deficit/Hyperactivity Disorder; PTSD: Post-Traumatic Stress Disorder

\section{Case Description}

Dirk is 8 years old. While his IQ is lower than average, his primary limitation is (social) adaptive functioning. Adaptive behavior can be divided into conceptual skills (such as language skills and the comprehension of time, numbers and money), social skills (such as communication skills and social problem solving) and practical skills (such as personal care and the use of transportation). Individuals are considered to present with significantly limited adaptive behavior when they fall short in one or more of these areas and do not meet age- and culture specific expectations [3]. Dirk has significant disabilities with regards to conceptual (concentration, learning and automation) and social skills.

Dirk is hyperactive, anxious, impulsive, has angry moods and has trouble playing with others. In addition to MID, Dirk has been diagnosed with attention-deficit/hyperactivity disorder (ADHD) and post-traumatic stress disorder (PTSD). Children and young ones with MID are at a higher risk of PTSD, but symptoms are often not recognized and diagnosed as such, and therefore the condition frequently remains untreated [4].

Dirk lives with his biological mother and her current partner. During the first years of his life Dirk witnessed domestic violence, as his father would hit his mother in front of him. When Dirk was three years old, his mother fled with him to a "Women's Shelter", which is a shelter for victims of domestic violence. His father was sentenced to eight years in prison for assault. Dirk visits his father in prison once every three months, and his father calls him a few times a week.

Dirk attends specialized education, during which he has a teaching assistant who supports him in the classroom and specialized after-school care. In addition, Dirk is treated with 


\section{Global Journal of Intellectual \& Developmental Disabilities}

Methylphenidates to better control his hyperactivity and impulsivity.

Due to stagnation of his treatment process at another institution, Dirk was referred to Rivierduinen, Kristal, Center of psychiatry and intellectual disability. Upon referral, as is customary within MBT-C (a time-limited approach), a structured assessment was initiated. During this assessment the mentalizing capacities of Dirk and his mother were analyzed and the possibilities for treatment with MBT were assessed. Parental assessment and treatment sessions take place in parallel to the assessment and treatment of the child. This article does not discuss this part, but it should be noted that it is an integral part of the treatment's success.

\section{MBT-C Assessment Phase}

The assessment phase consisted of four diagnostic sessions, one of which was a combined session with Dirk and his mother, and the other three were with Dirk and his mother individually $[1,5]$. The first author of this article (MJ) was Dirk's therapist.

Dirk's mother is sensitive and responsive in her contact with Dirk. She is quite good at mentalizing about Dirk and has an eye for his needs. Dirk experiences a close and positive bond with his mother. When talking about the relationship with his father, Dirk mentions the lack of his presence. When describing family ties Dirk appears chaotic.

Dirk can show different behavior patterns. For example, he is physically calmer and more cooperative when he has taken his medication. The difference in behavior also seems to be related to the topic of conversation. Dirk shows more physical agitation when talking about his burdened past and he tries to avoid this topic. On the other hand, Dirk becomes very calm during sensopathic play (in the sand tray) in which the space around him is smaller, reducing the number of stimuli. He seems to enjoy simple games for young children like hide and seek, which he initiates himself: there is a focus then on shared attention and being seen. In his contact with his mother he expresses the need for regulation, by asking for a pacifier and physical closeness or contact.

When Dirk is calm and regulated, he is capable of sensing and observing physical cues from others, to mentalize about them, and to adjust his behavior accordingly. When Dirk is hyperactive and chaotic, however, he is too preoccupied with his own 'mind' to focus his attention on others, let alone mentalize about them. At these moments he shows unacceptable and challenging behavior, like being verbally aggressive, not listening and breaking the rules.

In general, Dirk seems to have little insight into what is happening to him internally. He only masters a small amount of words to describe how he feels and expresses his emotions primarily through behavior. He can quickly become overwhelmed with emotions such as anger, fear and panic, as he has few skills to calm himself down. In addition, imagination and reality can merge for Dirk. At these moments, he needs closeness and guidance from an adult.

Traumatized children, who are not yet able to mentalize about what has happened to them, frequently express themselves through body language and behavior, with their behavior strikingly often appearing as aggressive [6,7]. In addition, children with MID appear to have more difficulty with self-regulation skills, such as reflecting on their own behavior, thoughts and feelings [8]. As a result, these children respond in a reflexive nature, rather than based on a well-considered decision. Furthermore, children with MID regularly experience delays in language and speech development [9] and as a result they have less language available to express themselves. Dirk's affect regulation and mentalization are under pressure due to both his PTSD and MID.

During the assessment sessions, conversations with Dirk do not provide insight into which traumatic memories are still affecting him. He does not want to talk about his experiences in the "Women's Shelter" nor about the domestic violence he witnessed at home. During play-based activities, however, recurring themes such as violence, aggression, and domestic violence emerge. His playing activities are lively and full of emotion.

During the MBT-C assessment of a traumatized child, the protective and risk factors with respect to the trauma are assessed, as well as the mentalizing abilities of the child and its corresponding impact. Questions to consider are: when, for how long and where did the traumatic events take place, and who committed them? Was there someone who offered protection to the child, such as the angel in the nursery as described by Lieberman [10]? What can we say about the child's attention regulation skills, emotion regulation abilities and mentalizing capabilities? With regard to which aspects does the child still function well? What are his or her strengths? When is the child's functioning impaired and are there specific triggers linked to the trauma? In other words, which triggers induce a trauma reaction causing the child to lose his mentalizing ability? Can the trauma be discussed as a topic of conversation or is it avoided, eliminated or denied (dissociation)?

\section{Focus formulation and goals}

To conclude the assessment of MBT-C, an advisory meeting is held with the parents and the child. During this meeting a focus formulation for the therapy is presented, which serves as a focus for the treatment in which both the child and the parents feel seen and understood and can understand the purpose of the treatment. For the child this is a first step towards increasing the feeling of self-agency. It is important to note that an advisory meeting can quickly become too linguistic for children with MID, because the processing of verbal information is less effective than that of visually presented information [11]. To support the child and the spoken language, the use of drawings or objects can help to try to make internal processes of the child more explicit. During the 
advisory meeting the treatment goals for both the child and the parents are composed as well.

The treatment goals for Dirk were as follows:

Goal 1: Improve his attention regulation

- Dirk is aware in which moments he is calmer and which stimuli make him hyperactive.

- Dirk is able to focus more frequently on what is happening inside of him.

- Dirk can focus his attention on what can be seen or heard when observing others from the outside.

Goal 2: Improve his emotional regulation

- $\quad$ Dirk is aware that emotions come and go.

- Dirk has discovered ways to calm himself when he is angry, scared or sad.

Goal 3: Improve his mentalizing skills

- $\quad$ Dirk is increasingly capable of expressing what he thinks and feels in words.

- $\quad$ Dirk has initiated thinking about what others can think and feel.

- Dirk can distinguish between feelings from the past and those of the present.

- $\quad$ Dirk is capable of organizing and describing his feelings (he can provide a narrative) related to the domestic violence he experienced.

\section{Increasing epistemic confidence through coordination of care}

Due to his traumatic relational experiences Dirk exhibits a deep-rooted distrust, which manifests itself as distrust towards others, being closed-off from learning experiences, and having difficulty opening up to others. Within MBT-C this is called epistemic hypervigilance. Children who have experienced relational trauma cannot properly recognize new information as important or relevant and find it more difficult to generalize new information to another social context. These children, through their hostile behavior, cause others to keep their distance and very often feel misunderstood. Partly for this reason, collaboration with the wider social environment of the child is of great importance.

Many different care providers are involved with the family and they aim to collaborate across disciplines and to coordinate treatment goals. This collaboration allows Dirk to practice his MBT-C goals in other settings and enables his care providers to observe his needs outside of a therapeutic context. For example, observations during school and after-school activities can provide information as to what Dirk needs to learn to remain sufficiently regulated and to continue mentalizing.

\section{MBT-C Treatment}

\section{The First Phase}

In this phase, the treatment is mainly aimed at making contact with the body, increasing confidence in the child himself and his confidence in others, and improving attention regulation. Traumatized children often experience their bodies differently from non-traumatized children. Body signals are experienced differently, because of the child's epistemic hypervigilance, and they are often less mentalized and mirrored, so that the connection to what is being felt is less strong. Due to the hypervigilance, there is usually under- or over-regulation and a decreased sense of agency over the body [12]. Children usually have fewer words to describe what is felt and it is difficult for them to distinguish between their physical feelings and the potentially linked emotions. Symbolizing play remains difficult during this first phase. Instead, more physical, experiential play lays the foundation for learning to make contact with the body and increasing awareness.

\section{The weather forecast game [13]:}

Dirk (D) and the therapist (T) are sitting behind each other. Dirk has already been explained what the game entails: the person sitting behind the other person draws the weather forecast with his or her finger on the back of the other person. The person at the front (the weatherman) focuses his or her attention on what is being drawn and tries to guess the weather.

T: Okay, here we go Dirk.

T draws the first "weather forecast" on Dirk's back. Dirk looks at the ground and seems to shift his attention from the camera to the feeling on his back. T observes that Dirk has a shiver.

T: It tickles a bit, doesn't it?

$\mathrm{T}$ (is done drawing): So, weatherman, what will the weather be like tomorrow?

D (carefully): Sun.

T: Sun! Good job.

D nods when T says: "good job".

T: Now I'm going to make it a bit more difficult, pay close attention.

T draws a new shape and D laughs for a moment, shivers and responds to the tickling of the therapist's fingers by moving his body.

T (laughs): Tickle, tickle.

$\mathrm{T}$ (finished drawing the shape): what will the weather be like tomorrow?

D: Rain 
T: No, it's not rain, I'll do it again.

T now draws part of the shape and says: First this one, what is this?

D: A cloud.

T: Yes

T draws the second part (the sun) and asks: What is that?

D (thinking carefully): I don't know

$\mathrm{T}$ draws the shape again and says, as she draws the rays of the sun: With rays.

D: Sun

T: So, what kind of weather will it be tomorrow?

D: Cloudy, no, no, sun, sun.

D looks at the therapist and makes eye contact for a moment.

T: Sun and a little...?

D: Cloudy

T: Yes, great!

D observes himself on the webcam screen again and sticks out his tongue and makes all kinds of funny faces.

T: You are a fast guesser

D does not visibly respond to this compliment and continues making clicking noises and pulling funny faces.

$\mathrm{T}$ looks in the same direction as Dirk and says: funny right, that video?

Just like D, T makes a funny face and smiles (mirroring).

T: Can you do your funniest, funniest face?

D looks at $\mathrm{T}$ and makes eye contact.

T: Shall we do it together?

$\mathrm{T}$ and $\mathrm{D}$ both make funny faces. T pauses and looks at D, while D continues making a funny face. T: Or something like this?

$\mathrm{T}$ makes another funny face. $\mathrm{D}$ goes along with the change of movement and also makes another funny face.

T: We have been distracted a little together, do you see that?

D: Yes

T: Because of the video.

T puts her hand on Dirk's shoulder and says: Shall we continue guessing the weather?

D: Yes

D turns his eyes back to the ground so that he can focus on his body.

\section{Mentalizing about this interaction during the session}

The exercise itself is not mentalizing per se and was originally designed for Theraplay [14]. Nevertheless, dealing with the exercise can be mentalizing, which allows one to work on goal 1 , improving attention regulation. The therapist offered this game to Dirk because it is a physical game that offers physical closeness, requires literal attention for the body, and has a clear structure and a calm rhythm. At the start of treatment, this structure helps to teach how to focus on the most relevant stimuli. Due to the sensopathic element of this game Dirk is able to focus his attention surprisingly well on the tactile stimulus of the therapist's moving finger that draws on his back. The game attunes to his need for proximity and touch, which he exhibited during the assessment phase.

The connection between the physical experience of the game and the visible behavior of Dirk in the moment can be verbally identified, e.g. "I see that your body is calm during this game Dirk, do you also feel calm on the inside?" As a result, therapist and child work together on connecting what can be seen on the outside to what is felt on the inside.

Before the session the therapist evaluated how much tension this game would potentially evoke in Dirk, because he has had different learning experiences with regard to touch. With his mother Dirk has had positive experiences, such as cuddling and physical closeness, while in the relationship with his father physical proximity has also been threatening and frightening. At the start of the game, it can be observed that Dirk's 'arousal level' is slightly increasing. The therapist does not mention this explicitly at this point, but instead tries to contain the arousal by adopting an accepting attitude and by being predictable (by using the same sentences over and over). Mentalizing at this stage remains mainly implicit. It might be possible to investigate whether a small connection can be made already by distinguishing between pleasant and unpleasant ways of touching. In this situation, the therapist could make a marked distinction between Dirk and herself by saying that she likes the tickling feeling and asking how it feels for him. By giving words to her own inner world, by providing subtitles for herself ("I'm not going to look at the camera anymore, I have to pay close attention to my body") and making her own feelings explicit ("oh that makes me happy") the therapist promotes explicit mentalization. In this phase of the therapy, it is easier for Dirk when the other person mentions emotions and sensations. Given his lower linguistic skills, he needs to see and hear examples in order to develop an emotional vocabulary.

An important part of MBT-C treatment is peer-to-peer learning and supervision for the therapist. Reflecting together on the interaction in the playroom helps to develop awareness of what is, or is not, said, felt and done. The practitioner is surprised at the calmness Dirk demonstrates during the game. Looking back at the video during peer-to-peer learning, it is striking how little words the therapist uses with Dirk. Together with her colleagues 
she can consider whether she could have provided more words to describe what may be happening internally to Dirk or what is happening internally to her. She can reflect on what makes her behave in this manner with this specific child, and on whether she would do things differently with another child, for example a child who would be less likely to become overstimulated and distracted. It provides Dirk calmness when the therapist does not use too many words in addition to the tactile stimuli he is already experiencing. By simply saying "tickle, tickle," the therapist does try to provide words for his physical sensation. Later in the session, when the game is over, the therapist tells Dirk that the game seems to calm him down. He cannot mentalize about the calmness at this point, or what it is that makes him calmer during this game than, for example, when he is in the classroom. To support Dirk, the therapist thinks out loud about potential options "Could you be calmer now because there are only two of us?" Dirk is able to confirm this observation, but it is noticeable that mentalizing about calmness and hyperactivity does not yet match his interests and capacities. After answering, he looks around the room and turns his body towards the playhouse, showing that he much rather wants to play than talk.

During the observed contact moment, the therapist attempts to create joint fun and shared attention. Dirk's attention span is fleeting in his daily life, making that there are few moments during which he has real contact with others for an extended period of time. There is a moment during the game when Dirk gets distracted by the camera that is recording and on which Dirk can see himself. He makes funny faces, observes himself from a different perspective, and laughs at his own face. During this moment the therapist has gone along with his playfulness, validating his movement (towards the camera) and facial expressions. This is a moment that could also have evoked a need for limitation. Yet, by going along with Dirk's movement for a moment, mirroring his behavior and facial expressions, and then giving words to the switch of attention ("we are distracted together"), the contact and playfulness are maintained. By using words such as "we", "together" and "do you see that?" the therapist emphasizes shared attention. By placing a hand on his shoulder, she tries to help Dirk in a non-verbal way to switch his attention back from the camera to his body. Dirk does not show any unruly behavior in response and can easily switch his attention from the camera to the exercise. The therapist also validates Dirk by saying that he is a "fast guesser".

\section{The Middle Phase}

In this phase of the treatment, Dirk started to play more symbolic games. Symbolizing precedes mentalizing [1]. Dirk has played the same type of game several times. It is a game with two armies where one army (that of the therapist) wants to conquer the castle of the other army (that of Dirk). This never works and Dirk always wins: he defeats the therapist's army and his castle is not captured. Would Dirk use this game to process his experiences of domestic violence? By winning, he feels control and power in contrast to the helplessness and fear he may have felt during the domestic violence [15]. In the game described below, the therapist's army is allowed to visit Dirk's army in the castle. Before being allowed in, her army has had to promise that they will only visit and not fight.

D: The tanker is driving along with them.

$\mathrm{T}$ (own voice): oh right, well they are keeping a close eye on us, I can see that.

$\mathrm{T}$ (playing voice): O.K. we're going in.

D: Then they were inside.

$\mathrm{T}$ makes horse noices and says: We are inside.

D (sings): in peace they come.

T: We come in peace, Hello everyone. What a beautiful castle you have.

D (playing voice): Hi, yes, very nice.

D (own voice): and then they are startled.

D puts the tank in front of the therapist's army.

$\mathrm{T}$ makes a startled sound accompanied with corresponding facial expressions. She lets the horses' neigh. D makes a shooting sound.

T (high playing voice 1 ): What is that?

$\mathrm{T}$ (low reassuring playing voice 2 ): quiet horses, quiet.

T: Eh, why do you have a tank?

D: A tank, yes, that's a good question. Our tank, yes it can shoot, but no, I don't really want to shoot.

T: The horses are very scared.

D (in a soft, reassuring tone): Look horses, it's just a tank.

T: Oh, look horses, it is just a tank, it is not too bad.

T: Can we look around some more?

D: Of course, here are the tankers and here is our camp.

T: Is that where you sleep?

D: Yes, we sleep here, this one comes from us and we sleep here.

D: We go inside, this is our sleeping place.

T: Oh yeah, it's interesting to see all this on the inside.

D: Yes, there are a lot of us.

T: Yes, a lot (enlarged intonation).

D: Yes, and nobody took over our castle once, we managed to 
get many dead.

T: So, many people wanted to take over your castle?

D: And it never worked!

T: No, and you had to fight very hard for the castle.

D: Very hard, yes.

T: Right, then I understand that you are now very careful that we do not do this either. We just want to look around, we come in peace. But we do notice that it is a bit tense when people come into the castle.

D (makes eye contact): I have a question.

T: Yes?

D: Why is there a monkey on your team, can that monkey talk?

T: Yes, I can talk.

$\mathrm{T}$ (voice over): He asks good questions, he wants to know exactly what everything is for, that one soldier.

T: I can talk. I am a talking monkey.

D (whispers): How can you talk?

T: Because I am a 'toy monkey' and, in a game, anything is possible, and I am a talking monkey.

D: Do you have a robot arm?

T: Yes look! (sound of moving robot arm)

D: What is that?

T: A mechanical foot, which I got after an accident, so I can walk again.

D: They have come to fight; they want to fight.

T stops for a moment and has to readjust. It's an important moment, because earlier in the game, the military gave their word that they would come in peace.

$\mathrm{T}$ (own voice): They want to fight now, with whom? They have come in peace, right? Did they lie, after all?

D: Yes

D scans the knights and says: Scanner are they really here in peace?

The scan tool's answer is: Not this guy, they all lied, they lied!

D makes fighting noises.

T (playing voice): No, we didn't.

$\mathrm{T}$ (normal voice): They had given their word!

D: Huh?
$\mathrm{T}$ (own voice): This army has given its word and this army keeps its word. They have come in peace and they have not come to fight.

D makes scanner sounds and rescans the army.

T: We don't want to fight; we really just want to see the castle.

D: Now, I have scanned, and this is the truth. Men, they have really come in peace.

T: You may have had a lot of armies that wanted to fight in the past, but now we're here and

we come in peace.

D: Do you want to help us?

T: We would like to help you, yes, what can we help you with?

D: I know something, come along.

\section{Mentalize about this interaction}

This game takes place in a phase of the therapy in which the focus increasingly centers on mentalizing about one's own and other people's feelings, which is one of the last treatment goals. The therapist uses many ostensive cues in the game. As an active commentator, the therapist always tries to invite the child to expand the game further, sometimes through demonstration, sometimes by instruction, and by emphatically stepping in and out of the game [16]. The relationship with the therapist offers the security to learn to imagine different mental states for the self and others. Prior to this game, Dirk has played several games during which safety and insecurity, and distrust and trust were important themes. As is often seen with traumatized children, he plays the same type of game several times in order to organize and process all the different emotions involved. Developments can be seen in the game's theme, demonstrating how Dirk is searching for a way for his army to have contact others without starting to fight directly.

In this phase of the treatment in the game room, Dirk is able to focus his attention on the game much more quickly and to enact his emotions through the game. The game has a clear structure, and he can spend about twenty-five minutes with the same materials. Dirk has grown in this. In addition, it is striking that during the game he switches his own attention from his army to the therapist's army ("then you were very surprised"). He has started to mentalize more about what is happening within himself and the other. This is beautiful and moving to see.

Throughout the therapy, it is difficult to determine how the therapist can use certain moments in the game to safely transform implicit mentalizing to explicit mentalizing. She sometimes tries to pause the game ("stop and stand") and asks about the soldiers' feelings. When she asks if Dirk has ever felt the same way as one of the soldiers, he struggles to answer. He responds to this 
question with confusion. He appears to have difficulty with the switch in attention from the game material to his own experience, with switching between imagination and reality. By naming and validating as many emotions and needs within the game as possible ("I understand that you are paying such close attention") the therapist helps create the transitional space in which Dirk feels safe enough to play with different realities, without losing the pretend-mode (which would make the game too real). In addition, she tries to mirror Dirk and to validate his emotions by repeating his words and reinforcing them ("yes, a lot").

There is one moment when Dirk starts to whisper. This is when he sees a monkey with all kinds of guns in his hand. At that moment, Dirk's tension noticeably increases. The guns may be a trauma trigger for Dirk. The therapist gets the impression that, in that moment, Dirk quickly moves into the psychic equivalent mode, possibly forgetting that it is fantasy and not reality. For that reason, the therapist says that the monkey is a "toy monkey", making the distinction between fantasy and reality and in doing so lowering his tension. After this, Dirk resumes speaking in his normal voice.

Shortly after this moment, when the therapist has indicated that her monkey has a machine foot as a result of an accident, Dirk switches from an already alert, investigative attitude to fight mode. He has a "scanner" to assess whether the therapist's army is telling the truth. Dirk may be entering the teleological mode here: what I see is true, and what I see is a machine foot that can be used to fight. The therapist's words do not reach him as well as before; the soldier is less perceptible, and the arousal level increases. At the moment that Dirk changes to fight mode, the therapist has to switch and think. Intuitively, it was immediately clear that this was an important moment, but it took her a while to formulate the right words. The mentalization of the therapist was briefly on hold. In such situations, it can help to express one's own feelings, and the feelings of the game figures, so that the child can notice what effects his actions have on others.

It is an important moment in therapy, because it enables the distinction between feelings from the past and feelings from now. The alert attitude (can the other person be trusted?) that Dirk shows during the game corresponds with Dirk's attitude when establishing new contacts, such as during after-school care. It is therefore important for Dirk to experience multiple times that the adults that are in his life right now keep their promises and that they are predictable and safe.

We also know that in traumatized children, emotions from the past and now can merge quickly and that it is important to allow the brain to experience that the situation now is different from what it used to be [17]. While the hyper-alertness was functional in the past, it is no longer needed. After the distinction between past and present is made within the game, Dirk's posture changes and he physically steps back and allows the army to enter.
Managing arousal levels during MBT-C with traumatized children is a real challenge. Sometimes the arousal level needs to be lowered, while at other times it has to be raised. Like the moment when Dirk asks the therapist's army questions ("why do you have this?"). The therapist does respond to the inquiry ("he has good questions, he wants to know everything"), but she could have increased the tension a bit more. For example, by emphasizing her own feelings even more ("phew, what questions! I get the feeling that you don't trust us, is that correct?"). This also applies to the moments when the army is finally allowed to enter. There too she could have said something about her own inner world. During the game she indicated that it was interesting to see the castle (external), but she could also have said something about what is happening internally (e.g. "It makes me happy that I can now enter the castle") and she could have asked about Dirk's internal world ("how do you feel, now that we are inside?").

\section{The Final Phase}

During the last phase of the treatment, explicit attention was paid to the theme of saying goodbye. For the last session of the treatment, the therapist wrote a letter to Dirk in which she describes the therapy process in simple terms. Writing a final letter for the child is an option that can be used to create a narrative about the therapy process. A regular final evaluation, in which the treatment goals are evaluated and discussed, is too ambitious for Dirk. He is not capable of focusing his attention on such a conversation and, due to his MID, he is not yet able to draw connections between events over a longer period of time. In the written story of the letter, the therapist helps Dirk by giving him words describe the process he has gone through.

During the therapy, Dirk's mentalizing capacity started to develop, he was able to enact traumatic experiences, and developed a larger vocabulary for his inner experiences. Dirk remains a stimulus-sensitive child, in whom the degree of mentalizing is strongly correlated with the way in which others relate to his level of attention regulation. For this reason, a lot of attention was paid during the final treatment phase to a comfortable transfer to school and after-school care. This process helped to clarify to Dirk's environment which needs, feelings and intentions are behind his behavior. This strengthens the mentalized ability of the adults around him and makes them curious about the child behind the behavior. Limitations will always remain in children with MID. For that reason, it is extremely important to make the child's environment sensitive to what they need. Through this process, one can foster a mentalizing environment for the child [18].

\section{Conclusion}

Dirk has had 12 MBTC sessions, after assessment, as did his mother. This case study demonstrated that MBT-C is a suitable treatment method for Dirk, a traumatized boy with a mild intellectual disability. After finishing this therapy Dirk was less 
anxious, less angry and was able to put his own emotions and thoughts into words more often. He sometimes could mentalize explicitly about thoughts and feelings of others. And also Dirk had symbolised in play a narrative about what had happened and how this had an effect on him as a boy. In children with MID it is extra important to consider the developmental level at which they function and to adjust the interventions accordingly. One can think of the duration, the form, and the language level, as well as the extent to which mentalizing is left implicit or made explicit with the help of visual aids and experience-based activities. More research into the effectiveness of MBT-C treatments in children with MID would be valuable.

\section{References}

1. Midgely N, Ensink K, Lindqvist K, Malberg N, Muller N (2017) Mentalization-based treatment for children: A time-limited approach. Washington, DC: American Psychological Association. USA.

2. Dekker- van der Sande F, Sterkenburg P (2015) Mentaliseren kan je leren: introductie in Mentaliserende Bevorderende Begeleiding (MBB).

3. Douma J (2018) Jeugdigen en (jong volwassenen) met een licht verstandelijke beperking, kenmerken en de gevolgen voor diagnostisch onderzoek en (gedrags) interventies. Interne publicatie Landelijk KennisCentrum LVB.

4. Mevissen L, Didden R (2017). Systeemgerichte diagnostiek en behandeling van psychotrauma bij jeugdigen met een licht verstandelijke beperking. Onderzoek \& Praktijk 15(1): 6-14.

5. Muller N, Midgley N (2015) Approaches to assessment in time-limited Mentalization Based Therapy for Children (MBT-C). Frontiers in Psychology 6: 1063.

6. Ensink K, Bégin M, Godbout N, Normandin L, Fonagy P (2016) Mentalization and dissociation in the context of trauma: Implications for child psychopathology. Journal of Trauma and Dissociation 18(1): 11-30.

7. Muller N, Midgley N (2020) The Clinical Challenge of Mentalization Based Therapy with Children Who are in "Pretend Mode". Journal of Infant, Child, and Adolescent Psychotherapy 19(1): 16-24.

This work is licensed under Creative Commons Attribution 4.0 License DOI: 10.19080/GJIDD.2020.07.555706
8. Dermitzaki I, Stavroussi P, Bandi M, Nisiotou N (2008) Investigating Ongoing Strategic Behaviour of Students with Mild Mental Retardation: Implementation and Relations to Performance in a Problem-solving Situation. Evaluation \& Research in Education 21(2): 96-110.

9. Vandereet J, Maes B, Lembrechts D, Zink I (2011) Expressive vocabulary acquisition in children with intellectual disability: speech or manual signs? Journal of Intellectual and Developmental Disability 36(2): 91-104.

10. Lieberman A, Gosh- Ippen C, Van Horn P (2019) Blijf van mijn moeder af. Een handleiding voor ouer-knidpsychotherapie bij jonge kinderen die geweld of een andere traumatische gebeurtenis hebben meegemaakt. Uitgeverij Don't Hit My Mommy! A Manual for ChildParent Psychotherapy with Young Witnesses of Family Violence. Publisher Zero to Three. Nederlands.

11. Van der Molen M,Van Luit J, Jongmans M, Van der Molen M (2007) Het werkgeheugen van jongeren met een lichte verstandelijke beperking. Kind en adolescent 28(3): 88-96.

12. Vliegen N, Tang E, Meurs P (2017) Van kwetsuur naar litteken. Uitgeverij. Dutch.

13. Mets M (2017) Spelenderwijs verbinden en hechten met meer dan 100 spelletjes. Uitgeverij SWP Amsterdam. Nederlands.

14. Booth, Jernberg (2010) Theraplay Strengthen the attachment between parents and children through play. Hogrefe Uitgevers. Pp. 304.

15. Allen J (2018) Mentalization in the development and treatment of attachment trauma. Routledge. Pp. 362.

16. Verheugt Pleiter J, Schmeets M, Zevalkink J (2010) Mentaliseren in de kindertherapie. Uitgeverij: Koninklijke Van Gorcum BV. Mentalizing in Child Therapy: Guidelines for Clinical Practitioners. Karnac Books. UK.

17. Struik A, Blanken van B (2018) Onderzoek \& Praktijk: Traumabehandeling kan wel. De toepassing van de slapende honden methode bij jeugdigen en volwassenen met een verstandelijke beperking. LVB Onderzoek \& Praktijk 16(1): 5-6.

18. Bruijn, J de, Buntinx W, Twint B (2014) Verstandelijke beperking: definitie en context. Amsterdam SWP. Pp. 152.

\section{Your next submission with Juniper Publishers will reach you the below assets}

- Quality Editorial service

- Swift Peer Review

- Reprints availability

- E-prints Service

- Manuscript Podcast for convenient understanding

- Global attainment for your research

- Manuscript accessibility in different formats

( Pdf, E-pub, Full Text, Audio)

- Unceasing customer service

Track the below URL for one-step submission https://juniperpublishers.com/online-submission.php 